\title{
Crédito do BNDES, dependência de finança externa, e intensi- dade de P\&D nos setores da indústria brasileira (1998-2014)
}

\author{
Eduardo Correia de Souza ${ }^{1}$ \\ Priscila Fernandes Ribeiro ${ }^{2}$ \\ Eduardo Souza Mattos ${ }^{3}$
}

\section{Resumo}

Este trabalho busca testar se o BNDES desempenha um papel compensando potenciais imperfeições no mercado de crédito no que diz respeito a investimentos em P\&D. Para isso, propomos uma análise de regressão com interação inspirada em Maskus et al. (2012). Utilizamos dados de 22 setores das indústrias extrativa e de transformação no Brasil, tendo como fontes principais a PINTEC, o BNDES e a PIA, compreendendo 6 triênios a partir de 1998 até 2014. Nossos resultados oferecem algum suporte para a hipótese de um papel positivo do BNDES: o crédito do BNDES está mais positivamente correlacionado com a intensidade de P\&D em setores da indústria e períodos em que é maior a dependência de capital (financeiro) externo.

\section{Palavras-Chave}

Crédito do BNDES. Dependência de finança externa. Intensidade de P\&D.

\begin{abstract}
This paper tests if the BNDES (Brazilian National Development Bank) plays a role compensating potential credit market imperfections, with regard to $R \& D$ investments. To do that, we use a regression with interaction terms inspired in Maskus et al. (2012). We analyze data on 22 Brazilian industrial sectors, having the PINTEC, the BNDES and PIA as the main data sources, and covering 6 triennia from 1998 to 2014. Our results give some support to the hypothesis that BNDES played a positive role: BNDES loans are more positively correlated with R\&D intensity in industrial sectors and periods in which dependence on external finance is bigger.
\end{abstract}

- Gostaríamos de agradecer a dois pareceristas anônimos e ao editor da Estudos Econômicos pelo trabalho de revisão e decisão editorial nestes tempos de pandemia.

1 Professor. Insper Instituto de Ensino e Pesquisa - End.: Rua Quatá, 300, Vila Olímpia - SP - Brasil. E-mail: eduardocs@insper.edu.br. - ORCID: https://orcid.org/0000-0003-4093-5786.

2 Professora. Insper Instituto de Ensino e Pesquisa - End.: Rua Quatá, 300, Vila Olímpia - SP - Brasil. E-mail: priscilafrl@insper.edu.br. - ORCID: https://orcid.org/0000-0002-3482-1734.

3 Mestre pelo Insper Instituto de Ensino e Pesquisa. End.: Rua Quatá, 300 - Vila Olímpia - SP, Brasil. E-mail: eduardo_smattos@yahoo.com.br._ORCID: https://orcid.org/0000-0003-0920-3798. Recebido: 24/05/2019. Aceito: 20/08/2020.

Editor responsável: Dante Aldrighi

(c) (i) (5) Esta obra está licenciada com uma Licença Creative Commons Atribuição-Não Comercial 4.0 Internacional. 


\section{Keywords}

BNDES credit. Dependence on external finance. R\&D intensity.

\section{JEL Classification}

L6. 03. 032 .

\section{Introdução}

Há cerca de dez anos para cá, presenciamos na literatura econômica um aumento no interesse pelos efeitos do crédito fornecido via BNDES sobre os setores e firmas da indústria brasileira. Dentre outros estudos sobre o tema, podemos destacar Ottaviano e Sousa (2008), Ribeiro e DeNegri (2009), DeNegri, Maffioli, Rodriguez e Vázquez (2011), Machado, Parreiras e Peçanha (2011), Lazzarini, Musacchio, Bandeirade-Mello e Marconi (2014), Machado, Grimaldi, Albuquerque e Santos (2014), Bonomo, Brito e Martins (2015), Cavalcanti e Vaz (2017), Souza e Ottaviano (2018) e Machado e Martini (2019). O foco desses trabalhos usualmente recai sobre variáveis dependentes como produtividade (seja valor adicionado por trabalhador ou TFP), investimento em capital físico, resultados (ou restrições) financeiros, emprego, etc.

Um aspecto bem menos investigado é o gasto com Pesquisa e Desenvolvimento (P\&D). Segundo Bond et al. (2005) e Brown et al. (2009), dados os seus resultados incertos, o investimento em P\&D é relativamente mais arriscado; além disso, firmas inovadoras, intensivas em capital humano, possuem relativamente poucos ativos tangíveis que podem servir como colateral de crédito; finalmente, o desejo de preservar segredos de produção pode levar os inovadores a fornecer pouca informação sobre os projetos de $\mathrm{P} \& \mathrm{D}$ para potenciais fornecedores externos de crédito. Essas características tornariam o investimento em P\&D particularmente suscetível a imperfeições no mercado de crédito. Por outro lado, como se sabe, a finalidade principal de mecanismos de direcionamento de crédito em geral e dos bancos de desenvolvimento em particular é justamente compensar tais imperfeições (ver Stiglitz 1994 e Armendáriz de Aghion 1999). Surge daí a conjectura do presente trabalho: estaria o crédito do BNDES mais positivamente correlacionado com a intensidade de $\mathrm{P} \& \mathrm{D}$ em 
setores da indústria ou períodos em que é maior a dependência de capital (financeiro) externo?

Essa hipótese é testada usando uma abordagem inspirada em Rajan e Zingales (1998), e ainda mais em Maskus et al. (2012). Basicamente, esses últimos autores regridem a intensidade de $\mathrm{P} \& \mathrm{D}$ (gasto em $\mathrm{P} \& \mathrm{D} /$ valor adicionado) a nível da indústria contra uma interação da dependência de capital externo da indústria com medidas de desenvolvimento financeiro a nível nacional. Alternativamente, neste trabalho substituímos essas medidas pela razão entre os repasses do BNDES e o valor adicionado, a nível da indústria/setor. Um sinal positivo do coeficiente associado à interação é, então, interpretado como evidência de que o BNDES cumpre um papel compensando potenciais imperfeições no mercado de crédito, no que diz respeito a investimentos em $\mathrm{P} \& \mathrm{D}$.

A dependência de capital externo dos setores da indústria brasileira é medida aqui através de três proxies alternativas: A primeira, e mais familiar, é a de Klapper et al. (2006): setores com maior despesa de investimento em comparação com o "fluxo de caixa livre" teriam mais dependência de crédito externo. A segunda é uma medida de "tangibilidade", semelhante à usada em Maskus et al. (2012): setores com mais capital físico por trabalhador (ou maior relação capital/produto) teriam mais ativos tangíveis a serem oferecidos como colateral e, portanto, menor dependência de capital externo. A terceira é uma medida mais ampla de "liquidez": setores com maior relação receita líquida de vendas/valor adicionado teriam menor dependência de crédito.

Nosso trabalho utiliza dados ao nível de desagregação do setor CNAE (classificação nacional de atividade econômica) a 2 dígitos, para a indústria extrativa e de transformação. Embora isso nos restrinja a um painel com uma dimensão $N$ bastante pequena (22 setores), segundo Maskus et al. (2012) tanto a dependência de capital externo quanto a tangibilidade são características da indústria, em grande parte externas às firmas. ${ }^{1}$ Nossas principais fontes de dados são o BNDES, a PINTEC (para gastos com P\&D) e a PIA-IBGE (para valor adicionado, número de trabalhadores, construção do estoque de capital físico, receita líquida de vendas, etc.). O uso de dados abertos também nos permite dispor de um bom número de variáveis de controle, de diversas fontes, como BACEN (para investimento direto estrangeiro), RAIS-MTE (para escolaridade dos trabalhadores) e

${ }^{1}$ Maskus et al. (2012), pg. 74. 
Funcex (para exportações e importações dos setores). A única exceção, dado não aberto, é uma medida de concentração (índice de HerfindahlHirschman) obtida através de tabulação especial da PIA na SAR-IBGE. ${ }^{2}$ O período analisado é 1998-2014, abrangendo 6 triênios.

Nossos resultados fornecem evidência favorável ao papel do BNDES em compensar imperfeições no mercado de crédito, no que diz respeito a gastos com P\&D. Essa evidência é encontrada tanto quando a dependência de capital (financeiro) externo dos setores é medida como em Klapper et al. (2006), como quando utilizamos a medida de "tangibilidade" baseada no capital físico (de Maskus et al. 2012), e também com a medida mais ampla de "liquidez" dos setores, baseada na receita líquida de vendas.

Uma vez que na medida de Klapper et al. (2006) entra o próprio gasto em $\mathrm{P} \& \mathrm{D}$ (como parte das despesas totais de investimento), surge uma preocupação com a possível endogeneidade dessa variável. Na seção de robustez deste artigo, mostramos que nosso padrão de resultados se mantém quando, ao invés de utilizarmos a medida de dependência de finança externa para os setores da indústria brasileira, usamos a medida para os setores correspondentes da indústria dos EUA obtida por Rajan e Zingales (1998).

Retornando à literatura sobre os efeitos do crédito do BNDES, cumpre mencionar alguns trabalhos cujos escopos se aproximam do nosso, como o de Ribeiro e DeNegri (2009). Embora esses autores utilizem dados da Pesquisa de Inovação (PINTEC - IBGE), o objetivo deles é restringir a análise a uma subsample de empresas que tomaram crédito do BNDES a fim de adquirir máquinas e equipamentos associados a inovações. ${ }^{3}$ As conclusões são que o acesso a crédito do BNDES não tem efeito significante sobre a TFP das firmas, embora esteja positivamente correlacionado com maior investimento. Ao invés de utilizarem a "tangibilidade" como uma medida de independência de capital externo numa análise de interação à la Maskus et al. (2012) como fazemos aqui, Ribeiro e DeNegri (2009) consideram o estoque de capital físico por trabalhador como um instrumento para o crédito concedido pelo BNDES. Tal instrumento revela-se fraco quando esses autores controlam para efeitos fixos a nível da firma.

2 Utilizamos essa medida como uma variável de controle porque teorias de inspiração Schumpeteriana sugerem uma relação positiva entre concentração ou poder de mercado e gasto em P\&D. Ver Aghion et al. (2005).

3 Segundo os autores, esse tipo de investimento promoveria aumento da TFP, em contraposição a investimentos em capital físico que reagem a uma queda no custo do capital, e apenas promoveriam expansão da capacidade. 
Analogamente, encontramos em nossa amostra uma correlação muito próxima de zero entre a razão crédito do BNDES/valor adicionado e o estoque de capital físico/valor adicionado - sendo que uma forte correlação positiva indicaria que o BNDES estaria sendo ineficiente, ao fornecer crédito para setores com baixa dependência de capital externo.

Ainda mais próximos do nosso tema, Machado e Martini (2019) estudam o impacto do crédito do BNDES sobre o gasto em P\&D das firmas brasileiras. Embora o uso de microdados constitua uma grande vantagem em relação ao nosso trabalho (permitindo, por exemplo, lidar com problemas de seleção das firmas no acesso ao crédito do BNDES), Machado e Martini (2019) não analisam o efeito do crédito do BNDES em interação com a dependência de finança externa. Outra diferença relevante é que, enquanto nosso trabalho utiliza os desembolsos totais do BNDES (que aliviariam a restrição de crédito das firmas, incentivando assim o gasto em P\&D) Machado e Martini se restringem às linhas de crédito do BNDES que são voltadas diretamente para inovação. Finalmente, em contraste com nosso trabalho, Machado e Martini (2019) têm apenas a PINTEC e o próprio BNDES como fontes de dados.

O restante do artigo está organizado da seguinte maneira: a seção 2 traz uma descrição dos dados e da construção das variáveis; na seção 3 apresentamos o modelo de regressão adaptado de Maskus et al. (2012), bem como os resultados básicos da estimação; na seção 4 fazemos alguns testes de robustez; a seção 5 conclui. 


\section{Dados}

Na Tabela 1 abaixo apresentamos nossos dados primários e suas respectivas fontes, assim como as variáveis construídas e suas respectivas fórmulas:

Tabela 1- Fontes de dados e variáveis

\begin{tabular}{lll}
\hline \hline variável primária & sigla & fonte \\
\hline gasto em P\&D & P\&D & PINTEC-IBGE \\
desembolsos do BNDES (todas as linhas de crédito) & BNDES & BNDES \\
valor da transformação industrial & VTI & PIA-IBGE \\
trabalhadores (número médio ocupado na produção) & L & PIA-IBGE \\
salários & W & PIA-IBGE \\
receita líquida de vendas & RLV & PIA-IBGE \\
investimento (em capital físico) & I & PIA-IBGE \\
exportações + importações & EX+IM & Funcex \\
investimento direto estrangeiro & IDE & Bacen \\
\% de trabalhadores com ensino superior (capital humano) & $\mathrm{CH}$ & RAIS-MTE \\
índice de Herfindahl-Hirschman & IHH & PIA (tabulação SAR-IBGE) \\
dependência de finança externa & $\mathrm{DFE}-\mathrm{R} \& Z$ & Rajan \& Zingales (1998) \\
\hline variável construída & sigla & fórmula \\
\hline intensidade de P\&D & P\&D/VTI & idem à sigla \\
grau de abertura comercial & (EX+IM)/VTI & " \\
razão IDE-VTI & IDE/VTI & " \\
razão crédito do BNDES-VTI & BNDES/VTI & " \\
capital físico & K & método do inventário perpétuo \\
relação capital-produto & K/VTI & idem à sigla \\
fluxo de caixa livre & FCL & VTI - W \\
dependência financeira externa (à la Klapper) & DFE & (I + P\&D - FCL) / (I + P\&D) \\
independência financeira externa & IFE & RLV / VTI \\
\hline Fonte: tabela laborada pelos autores & & \\
\hline
\end{tabular}

Fonte: tabela elaborada pelos autores

Neste trabalho, utilizamos dados em sua maioria abertos e disponíveis em sites do governo brasileiro. Para a variável dependente, intitulada intensidade de $P \& D$, utilizamos as informações publicadas pelo IBGE através da PINTEC - Pesquisa de Inovação. A PINTEC divulga gastos em inovação realizados pelos setores CNAE (classificação nacional de atividade econômica), a dois dígitos de desagregação, com frequência trienal, e correspondendo ao último ano do triênio.

Por causa dessa frequência trienal e da estratégia de identificação que adotamos, todos os dados que tinham originalmente frequência anual foram aqui consolidados em triênios: para as variáveis de fluxo, como por exem- 
plo o VTI (valor da transformação industrial) dos setores, valores anuais em R \$ constantes foram somados a fim de compor o VTI trienal. Já para variáveis de estoque, como capital físico, consideramos a média dos anos que compõem o triênio; o mesmo é feito com o número de trabalhadores - de modo que, por exemplo, o produto trienal por trabalhador reflete o quanto, em média, um trabalhador produziu em 3 anos.

Na dimensão $T$, nosso painel de dados compreende os 6 triênios já cobertos e publicados pela PINTEC. Na dimensão $N$, foram analisados apenas os setores a dois dígitos que compõem o que a CNAE chama de Indústria de Transformação e Indústria de Extração. No apêndice A é possível verificar a tabela de correspondência entre os setores considerados neste trabalho (numerados de 1 a 22) e os setores CNAE 1.0 e 2.0.

Todas as variáveis monetárias utilizadas neste estudo foram publicadas em valores correntes, e daí convertidas em moeda constante de 2016 (ano-base). Dados publicados em moeda estrangeira, tais como importações, exportações e investimento direto estrangeiro, foram inicialmente convertidos para moeda nacional através da taxa de câmbio média do período, para posteriormente serem transformados em moeda constante. O deflator usado para a conversão dos valores correntes é construído a partir do índice de inflação IPA-DI (taxa anual) do IBRE-FGV, desagregado por setor CNAE a 2 dígitos. ${ }^{4}$ As exceções de variáveis que não são deflacionadas usando o IPA do setor CNAE correspondente, e sim o IPA agregado geral ("todos os itens"), são: os desembolsos do BNDES e o investimento direto estrangeiro (porque, a nosso ver, trata-se de recursos externos, e não provenientes do próprio setor), e também o estoque de capital físico.

Nas subseções abaixo, apresentamos detalhes e gráficos das principais variáveis utilizadas neste estudo.

\footnotetext{
${ }^{4}$ Agradecemos a Silvia Mattos por nos fornecer a versão mais atualizada dos índices IPA.
} 


\subsection{Intensidade de $P \& D$}

Os gastos com $\mathrm{P} \& \mathrm{D}$ considerados neste trabalho foram obtidos através da soma de uma série de dispêndios divulgados na PINTEC (Pesquisa de Inovação - IBGE): Atividades internas de P\&D; Aquisição externa de P\&D; Aquisição de outros conhecimentos externos; Aquisição de Software; Aquisição de máquinas e equipamentos; Treinamento; Introdução das inovações tecnológicas no mercado; Projeto industrial e outras preparações técnicas. A publicação é trienal, abrangendo os triênios 1998-2000, 20012003, 2003-2005, 2006-2008, 2009-2011 e 2012-2014. As informações são detalhadas pelos setores e subsetores das Indústrias Extrativas e de Transformação seguindo-se a CNAE 1.0 até o triênio 2006-2008, e a CNAE 2.0 posteriormente.

O Gráfico 1 abaixo mostra a evolução da intensidade de P\&D (gastos com $\mathrm{P} \& \mathrm{D}$, como proporção do valor da transformação industrial) ${ }^{5}$ dos seguintes setores a 1 dígito CNAE: indústria extrativa e indústria de transformação.

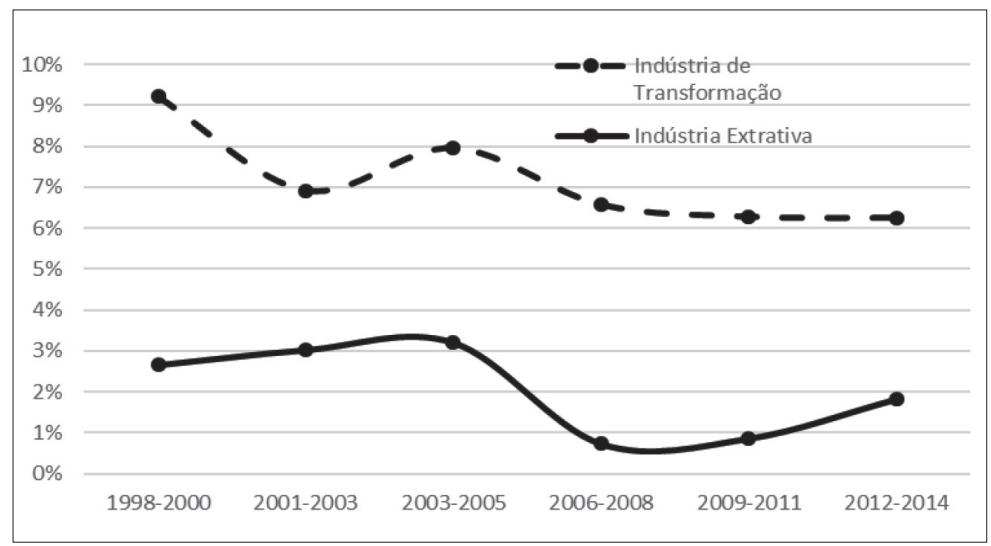

Gráfico 1 - Evolução dos gastos totais com P\&D como proporção do Valor da Transformação industrial (P\&D/VTI)

Fonte: Elaborado pelos autores, a partir dos dados da PINTEC e da PIA-IBGE

5 O VTI (valor da transformação industrial) dos setores CNAE é divulgado pela PIA (Pesquisa Industrial Anual) - IBGE, e consiste na diferença entre VBPI (Valor Bruto da Produção Industrial) e COI (Custos das Operações Industriais). Como o valor adicionado propriamente dito só passa a ser divulgado na PIA a partir do ano 2000, usamos aqui o VTI como uma medida equivalente. Inspecionando os dados da PIA, de fato constata-se que VTI e valor adicionado praticamente coincidem. Ao longo do texto, como se poderá notar, utilizamos o VTI para "normalizar" a maioria das variáveis. 


\subsection{Desembolsos do BNDES}

Os dados referentes aos desembolsos do BNDES são públicos e disponibilizados para download na página BNDES Transparência. Os valores divulgados têm periodicidade mensal e são detalhados por setor CNAE 2.0 e por tipo/linha de crédito. Uma vez que a hipótese adotada neste trabalho é que o BNDES contribui para o investimento em P\&D ao reduzir a restrição de crédito das empresas, num primeiro momento vamos considerar o total de desembolsos do BNDES por setor, i.e., todas as linhas de crédito somadas, e não apenas o crédito earmarked para inovação (FINEM, FUNTELL, FUNTEC, MPME inovadora, etc.).

O Gráfico 2 abaixo mostra a evolução, através dos 6 triênios da nossa amostra, dos desembolsos do BNDES como proporção do VTI para os setores CNAE 1 dígito da indústria extrativa e de transformação. Como se pode ver, houve um aumento significativo no montante de crédito que o BNDES disponibilizou para as indústrias extrativas no triênio 2006-2008, e para as indústrias de transformação no triênio 2009-2011. Em contrapartida, entre os anos 2012 e 2014, houve uma forte retração. De acordo com o site do BNDES Transparência, em 2010 houve uma capitalização excepcional de R \$24,7 bilhões na Petrobras que acabou elevando o montante daquele ano. Esse fato é observável nos dados que coletamos, já que a indústria denominada pela CNAE de Coque, Petróleo e Combustível recebeu como desembolso total em 2010 o montante de $\mathrm{R} \$ 28,7$ bilhões, enquanto que em 2011 essa mesma indústria recebeu $\mathrm{R} \$ 4,5$ bilhões (valores correntes). A partir de 2013, os desembolsos sofreram uma forte queda, influenciada pela política de ajuste fiscal do governo, com o fim dos empréstimos do Tesouro Nacional ao BNDES. 


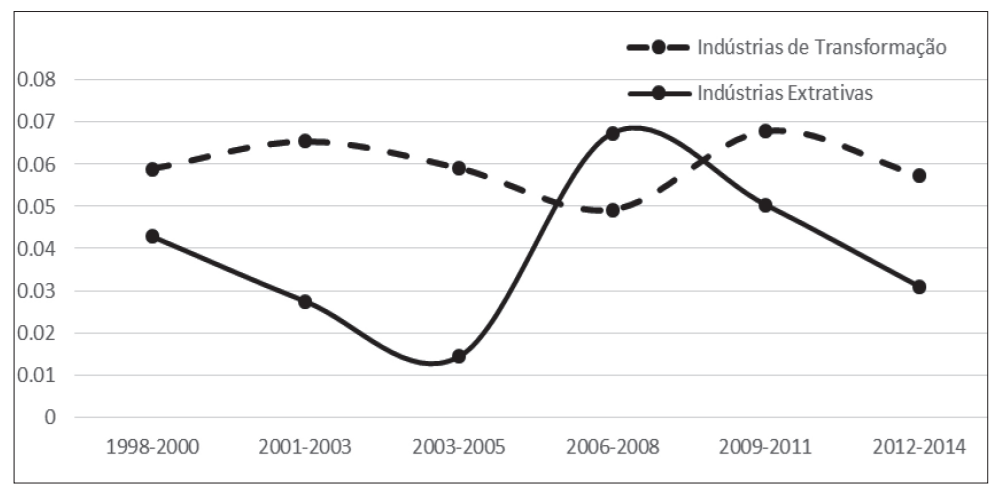

Gráfico 2 - Desembolsos do BNDES como proporção do Valor da Transformação Industrial (BNDES/VTI)

Fonte: Elaborado pelos autores, a partir dos dados do BNDES-transparência e da PIA-IBGE

\subsection{Dependência financeira externa (à la Klapper et al. 2006)}

Talvez a medida de dependência de finança externa mais consolidada hoje em dia na literatura seja a proposta na fórmula de Klapper et al. (2006): a diferença entre o investimento e o fluxo de caixa livre, dividida pelo investimento. Ao adaptarmos aqui essa fórmula, consideramos como "investimento" a soma do investimento em capital físico com o gasto em $\mathrm{P} \& \mathrm{D}$; e consideramos como fluxo de caixa livre a diferença entre o valor da transformação industrial (ou "valor adicionado") e os salários. À fórmula assim adaptada damos o nome de DFE. ${ }^{6}$ O Gráfico 3 abaixo mostra a evolução da DFE para os setores CNAE 1 dígito da indústria extrativa e de transformação. Inspecionando nossos dados brutos, os movimentos em sentidos contrários nas duas indústrias no triênio 2009-2011 devem-se, de um lado, à queda acentuada do investimento (em capital físico) na indústria extrativa; e, de outro lado, a uma queda na lucratividade (fluxo de caixa livre) da indústria de transformação.

6 Ver a Tabela 1 acima, com a fórmula. Vale ressaltar que pela PIA-IBGE não dispomos de uma medida direta (contábil) de "fluxo de caixa", nem de "fluxo de caixa livre". 


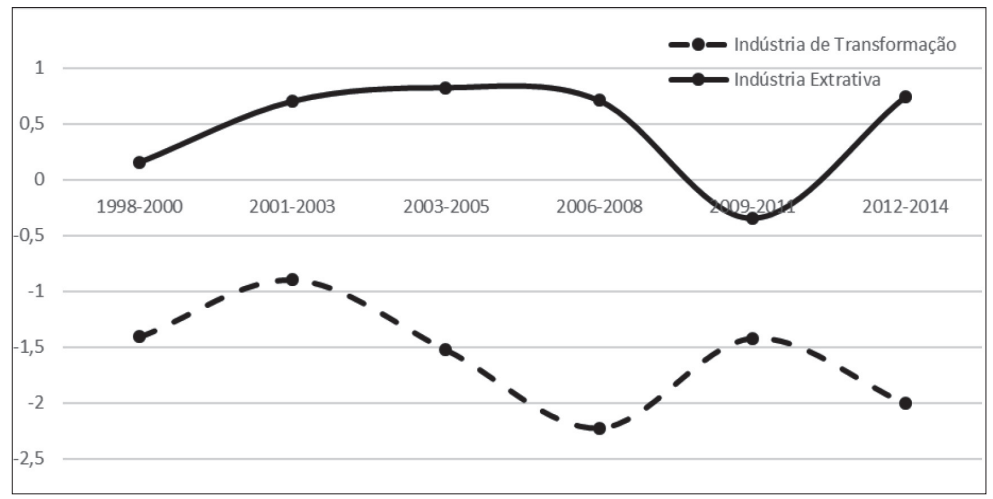

Gráfico 3 - A medida de Klapper et al. 2006 (DFE)

Fonte: Elaborado pelos autores, a partir dos dados da PINTEC e da PIA-IBGE

\subsection{Capital físico}

Conforme sugerido por Maskus et al. (2012), o estoque de capital físico seria uma proxy para a "tangibilidade" ou quantidade de colateral de crédito disponível para os setores da indústria.

Para a construção dessa variável, uma alternativa seria utilizar o método do inventário perpétuo, juntamente com a chamada "hipótese BEA" (Bureau of Economic Analysis). A dinâmica do capital seria dada por

$$
K_{i t}=(1-\delta) \cdot K_{i t-1}+I_{i t}
$$

Onde $K_{i t}$ é o valor do estoque de capital físico do setor $i$ no ano $t$; $\delta$ é a taxa anual de depreciação, que vamos aqui considerar idêntica entre setores, $\operatorname{com} \delta=0,07^{7}$; e $I_{i t}$ é o investimento do setor $i$ no ano $t .^{8}$

Pela hipótese BEA (Bureau of Economic Analysis), o estoque inicial de capital $\left(K_{i 0}\right)$ seria estimado supondo que no período $t=0$ o setor $i$ está em steady-state, de modo que:

7 Esse valor (7 \%) para a taxa de depreciação do estoque de capital físico é usual na literatura sobre crescimento econômico, como por exemplo em Ferreira et al. (2010).

8 Na literatura, é comum o uso do componente de investimento defasado $\left(I_{i t-1}\right)$. Como neste trabalho considerou-se que o capital físico do ano t $\left(K_{i t}\right)$ refere-se a 31/dezembro desse mesmo ano, foram utilizados os investimentos do próprio ano $\left(I_{i t}\right)$. 


$$
K_{i 0}=\frac{I_{i 0}}{g+\delta}
$$

Onde $I_{i 0}$ é o investimento inicial e $g$ a taxa de crescimento em steady-state.

Por (1) e (2), fica claro que as estimativas do estoque de capital assim obtidas são tanto mais dependentes do investimento inicial e da hipótese BEA quanto mais curta for a série de investimento. Ora, infelizmente isso é o que acontece no nosso caso: desejamos dispor de estimativas a partir de 1998 (ano inicial da PINTEC e do nosso painel), ao passo que o primeiro ano com dados de investimento da PIA é 1996! Por esse motivo, optamos aqui por uma abordagem diferente: A partir de 2000, a PIA-empresa passou a divulgar (na Tabela 1.6) o valor do ativo imobilizado a nível setorial, que então tomamos como o valor do estoque de capital físico para os anos 2000 a 2014. Para os anos anteriores do nosso painel (1998 e 1999), iteramos (1) para trás, de modo que, por exemplo, $K_{i 1999}=\frac{K_{i 2000}-I_{i 2000}}{(1-\delta)}$.

Por sua vez, os dados de investimento, necessários para a construção do estoque de capital físico de cada setor, também não são disponibilizados pela PIA em uma série específica. Este trabalho adota então uma composição de três outras séries como aproximação do investimento: as aquisições de ativos $\left(A q_{i t}\right)$, as melhorias $\left(M_{i t}\right)$ e as baixas $\left(B_{i t}\right)$ realizadas durante o ano.

$$
I_{i t}=A q_{i t}+M_{i t}-B_{i t}
$$

Ocorre, porém, que nem todas as empresas participantes da PIA declaram aquisições, melhorias e baixas. Para obter a série de investimento por setor, nos valemos da seguinte adaptação:

$$
I_{i t}=\left(\frac{A q_{i t}}{N_{A q_{i t}}}+\frac{M_{i t}}{N_{M_{i t}}}+\frac{B_{i t}}{N_{B_{i t}}}\right) \cdot N_{E m p_{i t}}
$$

Onde:

$N_{-} A q_{i t}=$ Número de empresas que informaram o montante gasto com aquisições de ativos;

$N \_M_{i t}=$ Número de empresas que informaram o montante gasto com melhorias de ativos;

$N_{-} B_{i t}=$ Número de empresas que informaram o montante gasto com baixas de ativos; 
$N_{-} E m p_{i t}=$ Total de empresas que participou da PIA, que também corresponde às empresas que apresentaram dados de produtos, receitas, custos, entre outros.

Ou seja, em (4) estamos supondo que, em média, as empresas não declarantes realizaram o mesmo investimento que as declarantes. Alves e Silva (2008) consideram essa imputação de dados válida ao compararem as empresas da PIA quanto aos padrões de crescimento da receita líquida e do pessoal ocupado: como não há diferenças significativas entre declarantes e não declarantes (de investimento), os autores concluem não haver um viés de declaração na pesquisa - caso houvesse, seria de se esperar que empresas não declarantes tivessem feito investimentos menores, o que se refletiria em menos receita líquida ou menos pessoal ocupado. ${ }^{9}$

O Gráfico 4 abaixo mostra a evolução da relação capital-produto (i.e., K/ VTI) para os setores CNAE 1 dígito da indústria extrativa e de transformação, ao longo dos 6 triênios da nossa amostra.

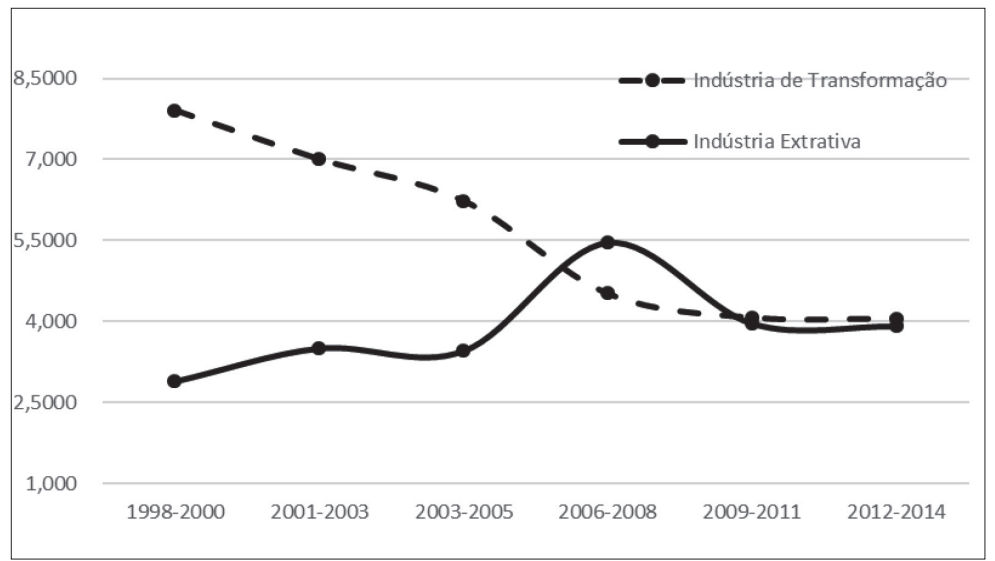

Gráfico 4 - A relação Capital-produto (K/VTI)

Fonte: Elaborado pelos autores, a partir dos dados da PIA-IBGE

9 Dispondo de microdados da PIA, Alves e Silva (2008) utilizam, em vez da simples expressão (4), propensity score matching para fazer a imputação de dados, agrupando firmas com características semelhantes. 


\subsection{Independência de Finança Externa (IFE)}

As informações referentes à RLV (Receita Líquida de Vendas) são publicadas pelo IBGE através da PIA (Pesquisa Industrial Anual). Esse dado corresponde à receita total de cada setor deduzida das vendas canceladas e descontos incondicionais, dos impostos sobre circulação de mercadorias (ICMS) e dos demais impostos e contribuições incidentes sobre as vendas e serviços, que guardam proporcionalidade sobre o preço de venda (Impostos sobre Serviços - ISS e Programa de Integração Social e Programa de Formação do Patrimônio do Servidor Público - PIS/Pasep), dos incidentes sobre as receitas de bens e serviços e das contribuições sobre faturamento (Contribuição para o Financiamento da Seguridade Social - COFINS). ${ }^{10}$

Em nosso trabalho, conforme discutiremos adiante, a relação RLV/VTI é tomada como uma medida de "disponibilidade de liquidez" ou de IFE ("independência de finança externa”) dos setores. O Gráfico B.1, no apêndice $B$, mostra a evolução da receita líquida de vendas como proporção do valor da transformação industrial para os setores CNAE 1 dígito da indústria extrativa e de transformação.

\subsection{Investimento Direto Estrangeiro}

A variável IDE (Investimento Direto Estrangeiro) será usada como controle em nossas regressões. Maskus et al. (2012) verificam que o influxo de IDE tem considerável impacto na intensidade de $\mathrm{P} \& \mathrm{D}$ dos setores industriais dos países da OCDE, sendo um dos fatores que colaboram para o desenvolvimento financeiro nacional.

No Brasil, o IDE é publicado anualmente através do Banco Central, e apresenta valores em milhões de dólares americanos correntes por setor CNAE a 2 dígitos. No Gráfico B.2, apêndice B, mostramos a evolução do IDE como proporção do VTI para os setores CNAE 1 dígito da indústria extrativa e de transformação. Como se pode ver nesse gráfico, as indústrias extrativas passaram por dois picos de IDE, um correspondendo ao triênio 2001-2003, e outro ao triênio 2006-2008.

${ }^{10}$ Fonte: SIDRA - Sistema IBGE de Recuperação Automática 


\subsection{Abertura comercial}

Informações sobre Importações e Exportações são divulgadas pela Fundação Centro de Estudos do Comercio Exterior (Funcex) e foram obtidas através do Instituto de Pesquisa Econômica Aplicada - IPEA. Os dados têm frequência anual, e compreendem o período entre 1996 e 2016. Os valores são detalhados por setor a 2 dígitos através da classificação CNAE 1.0, e expressos em dólares correntes.

O valor total das importações somado ao das exportações, e daí dividido pelo VTI, dá origem ao que chamamos "grau de abertura comercial", variável utilizada como controle em nossas regressões. A ideia é que setores mais abertos estariam sujeitos a maior competição e, portanto, teriam maiores incentivos para inovar. ${ }^{11}$

Como se pode ver no Gráfico B.3, apêndice B, a representatividade dessa variável na produção dos setores é muito significativa, ficando acima de $100 \%$ para a indústria extrativa.

\subsection{Capital humano}

Existe uma ampla literatura (ver, por exemplo, Ang et al. 2010) onde o capital humano é tratado como um input na atividade de P\&D ou adoção de novas tecnologias. Aqui, optamos por usar como proxy para o $\mathrm{CH}$ (capital humano) dos setores a fração de trabalhadores com nível de educação superior completo. ${ }^{12}$

${ }^{11}$ Essa interpretação (em termos de competitividade externa) é a que cabe fazer a partir dos dados abertos de exportações e importações que utilizamos. Aqui, os fluxos de produtos classificados por NCM (Nomenclatura Comum do Mercosul) reportados pela Secretaria de Comércio Exterior são convertidos em fluxos de produtos CNAE através da CONCLA-IBGE. Uma alternativa, disponível também na Funcex, é tomar, digamos, os valores das importações (de quaisquer produtos, independente do setor de origem) e associá-los à CNAE das firmas importadoras. Com isso, teríamos uma medida de abertura comercial sujeita a uma interpretação diferente: setores, digamos, com maiores fluxos de importações seriam setores com canais mais abertos para absorção internacional de tecnologia - sem dúvida, um aspecto também relevante para nossa variável de estudo (intensidade em P\&D). Agradecemos a um parecerista anônimo por chamar nossa atenção para essas diferentes interpretações.

12 Também encontramos resultados semelhantes utilizando uma medida à la Bils e Klenow (2000), onde o capital humano do setor i é dado por $h_{i t}=e^{\varphi \cdot u_{i t}}$, onde $u_{i t} \equiv$ número médio de anos de estudo dos trabalhadores do setor i no ano t ; e $\varphi \equiv$ parâmetro que representa a elasticidade do salário em relação ao número de anos de estudo. 
A proporção de trabalhadores com nível superior está disponível na base estatística da Relação Anual de Informações Sociais - RAIS, do Programa de Disseminação de Estatística do Trabalho - PDET, do Ministério do Trabalho e Emprego - MTE. A frequência da RAIS é anual e os dados são classificados através dos setores da CNAE 95 para os anos anteriores a 2006, e pela CNAE 2.0 para os anos compreendidos entre 2006 e 2014. A fim de obter a variável $\mathrm{CH}$ (capital humano) para os triênios da nossa amostra, tomamos uma média simples dos dados anuais.

O Gráfico B.4, apêndice B, mostra a evolução da proporção de trabalhadores com nível superior para os setores CNAE 1 dígito da indústria extrativa e de transformação. É clara a tendência de aumento nessa proporção ao longo do tempo: tomando uma média simples entre os nossos 22 setores industriais, ela aumentou de $7 \%$ no triênio $1998-2000$ para $11 \%$ no triênio 2012-2014. Ainda pelo Gráfico B.4, a tendência de aumento é muito mais forte na indústria extrativa.

\section{9. Índice de Herfindahl-Hirschman}

Teorias de inspiração Schumpeteriana propõem uma relação positiva (ou em "inverted U") entre inovação ou gasto em P\&D e poder de mercado. Evidências empíricas nesse sentido já foram encontradas por Aghion et al. (2005) para setores da indústria do Reino Unido, e por Correia de Souza e Moita (2011) para setores da indústria brasileira. Aqui, utiliza-se como medida de poder de mercado uma tradicional medida de concentração, que é o IHH (Índice de Herfindahl-Hirschman). O IHH foi construído através de uma tabulação especial encomendada junto à SAR-IBGE, e cumpre destacar sua representatividade, por abranger todas as firmas respondentes da PIA-IBGE no período da nossa amostra (1998-2014). ${ }^{13}$

A partir dos microdados de RLV (receita líquida de vendas) das empresas da PIA (IBGE), calculamos primeiramente a participação (market share) da empresa $i$ pertencente ao setor (CNAE) $J$ :

$$
P_{i}=\frac{R L V_{i}}{\sum_{j \in J} R L V_{j}}
$$

13 Agradecemos a Glaucia Ferreira (IPEA e IBGE) pelo suporte técnico. 
Ou seja, é a receita da empresa $i$ dividida pela soma das receitas de todas as empresas $j$ pertencentes ao setor $J$ (incluindo $i$, obviamente). O IHH do setor $J$ é dado por:

$$
I H H_{J}=\sum_{j \in J} P_{j}^{2}
$$

Inspecionando (6), fica evidente que quanto maior a concentração (maior participação de um número reduzido de firmas) maior o IHH. O Gráfico B.5, apêndice B, mostra a evolução do IHH para os setores CNAE 1 dígito da indústria extrativa e de transformação. Nota-se que, no período analisado, as indústrias de transformação apresentaram uma queda na concentração, ao passo que a indústria extrativa teve um aumento.

Resumindo a descrição dos nossos dados, a Tabela 2 traz a média (através dos triênios da amostra) de cada variável para cada um dos nossos 22 setores industriais: ${ }^{14}$

Tabela 2 - média (cross-triênios) das variáveis de estudo por setor da indústria

\begin{tabular}{|c|c|c|c|c|c|c|c|c|c|c|}
\hline Setor & P\&D/VTI & $(E X+I M) / V T I$ & IDE/VTI & BNDES/VTI & IFE & $\mathrm{CH}$ & DFE & K/VTI & $\mathrm{IHH}$ & DFE - R\&Z \\
\hline 1 & 0.021 & 2.331 & 0.067 & 0.011 & 1.654 & 0.154 & 0.466 & 3.87 & 0.18 & - \\
\hline 2 & 0.054 & 0.607 & 0.048 & 0.044 & 2.871 & 0.048 & -0.741 & 2.903 & 0.053 & 0.11 \\
\hline 3 & 0.03 & 0.989 & 0.016 & 0.003 & 2.086 & 0.14 & -5.228 & 4.159 & 0.265 & -0.45 \\
\hline 4 & 0.067 & 0.626 & 0.025 & 0.06 & 2.506 & 0.033 & -1.33 & 6.437 & 0.009 & 0.4 \\
\hline 5 & 0.039 & 0.191 & 0.002 & 0.033 & 2.229 & 0.017 & -1.391 & 2.233 & 0.006 & 0.03 \\
\hline 6 & 0.049 & 0.913 & 0 & 0.044 & 2.38 & 0.014 & -1.764 & 2.378 & 0.014 & -0.14 \\
\hline 7 & 0.061 & 0.772 & 0.025 & 0.055 & 2.055 & 0.02 & -0.685 & 4.977 & 0.025 & 0.28 \\
\hline 8 & 0.051 & 0.598 & 0.045 & 0.087 & 2.117 & 0.081 & -0.589 & 8.915 & 0.028 & 0.15 \\
\hline 9 & 0.056 & 0.06 & 0.024 & 0.008 & 1.704 & 0.097 & -2.989 & 5.128 & 0.05 & 0.2 \\
\hline 10 & 0.025 & 0.287 & 0.011 & 0.044 & 1.622 & 0.125 & -2.503 & 2.236 & 0.718 & 0.33 \\
\hline 11 & 0.08 & 1.069 & 0.085 & 0.031 & 2.909 & 0.187 & -1.14 & 4.589 & 0.02 & 0.855 \\
\hline 12 & 0.074 & 0.507 & 0.044 & 0.038 & 2.553 & 0.049 & -0.727 & 4.668 & 0.012 & 0.23 \\
\hline 13 & 0.06 & 0.276 & 0.042 & 0.042 & 2.064 & 0.038 & 0.508 & 8.231 & 0.014 & 0.06 \\
\hline 14 & 0.072 & 1.011 & 0.122 & 0.066 & 2.551 & 0.092 & -2.075 & 6.684 & 0.035 & 0.09 \\
\hline 15 & 0.062 & 0.382 & 0.017 & 0.029 & 2.24 & 0.042 & -1.42 & 2.482 & 0.006 & 0.24 \\
\hline 16 & 0.11 & 3.912 & 0.297 & 0.175 & 2.912 & 0.111 & -0.13 & 35.026 & 0.035 & 1.06 \\
\hline 17 & 0.088 & 1.075 & 0.063 & 0.046 & 2.638 & 0.148 & -0.305 & 1.786 & 0.026 & 0.77 \\
\hline 18 & 0.076 & 1.3 & 0.045 & 0.067 & 2.438 & 0.099 & -4.156 & 1.162 & 0.011 & 0.45 \\
\hline 19 & 0.12 & 1.008 & 0.123 & 0.103 & 3.046 & 0.127 & -0.68 & 7.197 & 0.048 & 0.39 \\
\hline 20 & 0.171 & 2.015 & 0.033 & 0.849 & 2.514 & 0.112 & -0.819 & 0.988 & 0.204 & 0.31 \\
\hline 21 & 0.065 & 0.257 & 0.001 & 0.033 & 2.369 & 0.07 & -1.778 & 4.072 & 0.006 & 0.24 \\
\hline 22 & 0.099 & 0.343 & 0.131 & 0.008 & 2.543 & 0.081 & -3.278 & 2.109 & 0.083 & 0.47 \\
\hline
\end{tabular}

Fonte: Elaborado pelos autores.

${ }^{14} \mathrm{O}$ apêndice $\mathrm{A}$ traz a descrição dos setores. Note que alguns de nossos setores agregam dois ou mais setores das classificações originais CNAE 1.0 e/ou 2.0. O motivo da agregação é justamente fazer uma concordância entre as versões da CNAE, no que procuramos seguir a CONCLA (comissão nacional de classificação) - IBGE. 
Finalmente, cumpre mencionar aqui uma limitação no que diz respeito a variáveis que capturam "desenvolvimento financeiro" a nível setorial. Em nosso trabalho, elas são os repasses do BNDES e o investimento direto estrangeiro. Além dessas, seria importante dispor do crédito privado (não direcionado), ou "bank finance dependence" como em Carlin e Mayer (2003). Contudo, a revisão da estrutura de dados de crédito efetuada pelo BACEN em 2015, detalhando as operações de crédito de acordo com o setor (CNAE) de atividade econômica dos tomadores, vai retroativamente até 2007 apenas - o que nos levaria a perder três dos seis triênios da PINTEC em nossa amostra.

\section{Metodologia e resultados}

Conforme discutido na introdução, utilizamos uma adaptação do modelo de regressão de Maskus et al. (2012) a fim de testar se o BNDES cumpre um papel compensando potenciais imperfeições no mercado de crédito, no que diz respeito a investimentos em $\mathrm{P} \& \mathrm{D}$. Uma variável que capturava "desenvolvimento financeiro" a nível nacional em Maskus et al. (2012) ${ }^{15}$ é substituída, em nosso modelo, pelos desembolsos do BNDES para o setor como proporção do valor da transformação industrial do setor. Essa variável, então, é interagida com uma medida de dependência ou independência de finança externa do setor. Formalmente:

$\frac{P \& D_{i t}}{V T I_{i t}}=\beta_{0}+\beta_{1} \cdot \frac{B N D E S_{i t}}{V T I_{i t}}+\beta_{2} \cdot \operatorname{dep}_{i t}+\beta_{3} \cdot \frac{B N D E S_{i t}}{V T I_{i t}} \cdot d e p_{i t}+\tilde{\beta}_{4} \cdot \underset{\sim}{X_{i t}}+\varepsilon_{i t}$

onde:

$$
\begin{aligned}
& i=\text { setor e } t=\text { ano } \\
& \frac{P \& D}{V T I}=\text { intensidade de gastos com P\&D } \\
& \frac{B N D E S}{V T I}=\begin{array}{l}
\text { razão entre desembolsos do BNDES e valor da transformação } \\
\text { industrial }
\end{array}
\end{aligned}
$$

${ }^{15}$ Uma medida para essa variável de Maskus et al. (2012) seria, por exemplo, o crédito privado como proporção do PIB de um país. Nos trabalhos originais (Rajan \& Zingales 1998, e Maskus et al. 2012), é possível que o efeito de interação entre dependência de finança externa (do setor) e o desenvolvimento financeiro (do país) reflita não linearidades e "seletividade" no uso do crédito, i.e., que, digamos, um aumento na razão crédito/PIB do país não beneficie igualmente todos os setores. Ao invés de uma desvantagem, nós consideramos como uma vantagem do nosso trabalho olharmos para o crédito (do BNDES) efetivamente alocado/disponibilizado para os diferentes setores. 


$$
\begin{aligned}
& \operatorname{dep}=\text { dependência (ou independência) de finança externa } \\
& \underset{\sim}{X}=\text { vetor de controles } \\
& \varepsilon=\text { erro aleatório }
\end{aligned}
$$

A predição fundamental do modelo é que $\beta_{3}$ seja positivo quando dep capturar dependência de finança externa; e negativo quando dep capturar, na verdade, independência de finança externa. A intuição é a usual para interação entre variáveis numa regressão: dado um certo volume relativo de crédito do BNDES (BNDES/VTI), o impacto positivo na intensidade de $P \& D$ será tanto maior quanto maior a dependência de finança externa.

Um problema metodológico surge pelo fato de os gastos em $\mathrm{P} \& \mathrm{D}$ divulgados pela PINTEC se referirem apenas ao último ano do triênio da pesquisa; enquanto as variáveis oriundas de todas as outras fontes têm frequência anual ou mensal. A fim de não perdermos informação sobre os primeiros anos do triênio, optamos aqui por usar as médias trienais das variáveis explicativas e controles. ${ }^{16}$ De modo que, por exemplo:

$$
\frac{P \& D_{i t}}{V T I_{i t}}=\frac{P \& D_{i T_{t}}}{V T I_{i} T_{t}} \quad \text { e } \quad \frac{B N D E S_{i t}}{V T I_{i t}}=\frac{\sum_{\tau=0}^{2} B N D E S_{i} T_{t}-\tau}{\sum_{\tau=0}^{2} V T I_{i} T_{t}-\tau}
$$

, onde $T_{t}$ é o último ano do triênio $t$.

A estratégia de identificação em (8) é representada na Figura 1 abaixo:

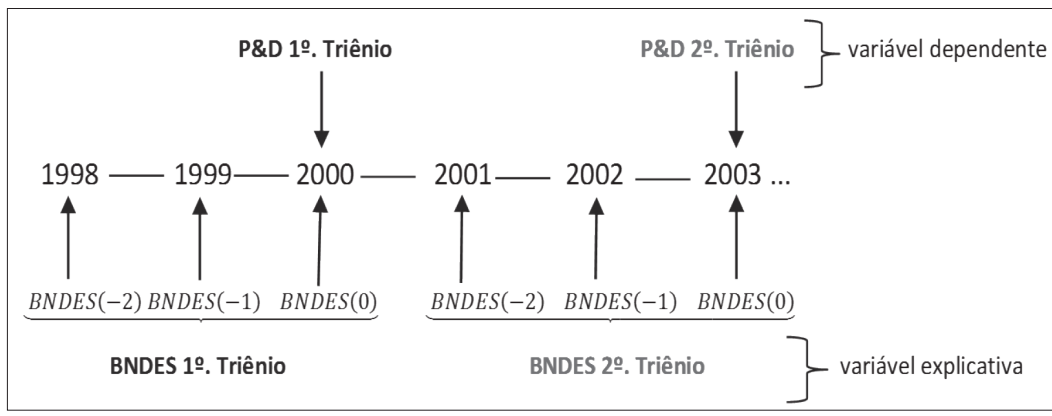

Figura 1 - Merging numa base trienal:

Fonte: elaborada pelos autores ${ }^{16}$ Uma exceção, inevitável, é a variável DFE. Porque ela envolve, dentre outras coisas, justamente os
investimentos em P\&D, que só estão disponíveis para o último ano da amostra. 
Na Tabela 3 abaixo apresentamos os resultados da estimação de (7) por mínimos quadrados, com efeitos fixos de ano e de setor, e erros-padrão robustos agrupados (clusterizados) por setor. Foram utilizadas como variáveis de controle IDE/VTI (investimento direto estrangeiro como proporção do valor da transformação industrial), $\frac{E X+I M}{V T I}$ (grau de abertura comercial), $\mathrm{CH}$ (capital humano) e $I H H$ (índice de Herfindahl-Hirschman), descritas na seção 2 acima. A Tabela 3 traz três conjuntos de resultados, conforme a proxy utilizada para dep: respectivamente, DFE (a tradicional medida de Klapper et al. 2006, baseada na diferença entre o investimento e o fluxo de caixa livre), K/VTI (relação capital-produto, também chamada de "tangibility" por Maskus et al. 2012) e IFE (razão entre receita líquida de vendas e valor da transformação industrial). Note que, conforme discutido na seção 2 acima, essas duas últimas proxies capturam, na verdade, independência de finança externa. A motivação para o uso da IFE vem de Bond et al. (2005): segundo esses autores, em mercados de crédito menos desenvolvidos (como o Brasil, no nosso caso) a decisão de fazer P\&D das firmas seria mais dependente do fluxo de caixa corrente e da receita corrente de vendas. ${ }^{17} \mathrm{~A}$ ideia por trás de IFE é que, para um mesmo valor da transformação industrial, setores com maior receita de vendas disporiam de maior liquidez ou maior capital de giro, dependendo menos de finança externa.

\footnotetext{
${ }^{17}$ Note que tanto nossa variável IFE quanto a interpretação de Bond et al. (2005) se baseiam em receitas correntes. Em Inklaar e Koetter (2008), pelo contrário, uma alta taxa de crescimento do volume de vendas é interpretada como indicativa de maiores oportunidades de crescimento e, portanto, maior dependência de finança externa.
} 
Tabela 3 - resultados

\begin{tabular}{|c|c|c|c|c|c|c|}
\hline \multirow[b]{2}{*}{ BNDES/VTI } & \multicolumn{2}{|c|}{ dep = DFE } & \multicolumn{2}{|c|}{$\operatorname{dep}=\mathrm{K} / \mathrm{VTI}$} & \multicolumn{2}{|c|}{ dep $=$ IFE } \\
\hline & 12,944 & $0,8469^{* *}$ & $0,3832^{* * *}$ & $0,4192^{* * *}$ & $2.7203^{* *}$ & $2.2493^{* * *}$ \\
\hline & $(0,8048)$ & $(0,3055)$ & $(0,0238)$ & $(0,0539)$ & $(1.2080)$ & $(0.6173)$ \\
\hline \multirow[t]{2}{*}{ dep } & $-0,0206$ & $-0,0184$ & $0,0400^{* * *}$ & $0,0547^{* * *}$ & -0.1366 & -0.0629 \\
\hline & $(0,0195)$ & $(0,0125)$ & $(0,0022)$ & $(0,0116)$ & $(0.2992)$ & $(0.1425)$ \\
\hline \multirow[t]{2}{*}{ dep x BNDES/VTI } & 0,7256 & $0,6041^{* *}$ & $-0,0367^{* * *}$ & $-0,0525^{*}$ & $-0.9138^{* \star}$ & $-0.8118^{* * *}$ \\
\hline & $(0,4936)$ & $(0,2290)$ & $(0,0050)$ & $(0,0283)$ & $(0.3833)$ & $(0.2495)$ \\
\hline \multirow[t]{2}{*}{ Abertura/VTI } & & $0,2533^{* * *}$ & & $-0,1724$ & & $0.2544^{* * *}$ \\
\hline & & $(0,0735)$ & & $(0,1025)$ & & $(0.0815)$ \\
\hline \multirow{2}{*}{$\begin{array}{l}\text { Invest, Direto } \\
\text { Estrang,/VTI }\end{array}$} & & $0,5498^{* * *}$ & & $-0,1751$ & & $0.6121^{* * *}$ \\
\hline & & $(0,1621)$ & & $(0,4835)$ & & $(0.1525)$ \\
\hline \multirow[t]{2}{*}{ Ln Capital Humano } & & $-0,0683$ & & 0,0400 & & -0.0306 \\
\hline & & $(0,0591)$ & & $(0,0388)$ & & $(0.0602)$ \\
\hline \multirow[t]{2}{*}{$\mathrm{IHH}$} & & $0,7714^{*}$ & & 0,1664 & & 0.0628 \\
\hline & & $(0,4025)$ & & $(0,2348)$ & & $(0.7488)$ \\
\hline \multirow[t]{2}{*}{ Constante } & $0,3013^{* * *}$ & $-0,2168$ & $0,1138^{* * *}$ & $0,3023^{* *}$ & 0,6458 & 0,1154 \\
\hline & $(0,0526)$ & $(0,2188)$ & $(0,0174)$ & $(0,1435)$ & $(0,6871)$ & $(0,3869)$ \\
\hline No, Observações & 132 & 132 & 132 & 132 & 132 & 132 \\
\hline No, Setores & 22 & 22 & 22 & 22 & 22 & 22 \\
\hline Efeito Fixo Setor & Sim & Sim & Sim & Sim & Sim & Sim \\
\hline Efeito Fixo Ano & Sim & Sim & Sim & Sim & Sim & Sim \\
\hline Estimador Variância & Huber-White & Huber-White & Huber-White & Huber-White & Huber-White & Huber-White \\
\hline R-quadrado overall & 0,440 & 0,497 & 0,716 & 0,498 & 0,113 & 0,542 \\
\hline $\begin{array}{l}\text { R-quadrado } \\
\text { between }\end{array}$ & 0,513 & 0,468 & 0,664 & 0,288 & 0,012 & 0,547 \\
\hline R-quadrado within & 0,381 & 0,619 & 0,784 & 0,810 & 0,308 & 0,567 \\
\hline Estat, F & 6,878 & 157,2 & 3889 & 19108 & 3,358 & 523,6 \\
\hline Prob (F) & 0,0002 & 0,0000 & 0,0000 & 0,0000 & 0,0123 & 0,0000 \\
\hline $\begin{array}{l}\text { teste LM de } \\
\text { Inoue-Solo }\end{array}$ & 7,54 & 13,61 & 15,94 & 15,59 & 9,28 & 9,29 \\
\hline Prob(Inoue-Solo) & 0,581 & 0,137 & 0,068 & 0,076 & 0,412 & 0,411 \\
\hline
\end{tabular}

(1) Erro-padrão Robusto em parênteses.

(2) ${ }^{* * *} \mathrm{p}<0.01,{ }^{* *} \mathrm{p}<0.05,{ }^{*} \mathrm{p}<0.1$.

(3) Hipótese nula do teste de Inoue-Solo (2006) é de que, no painel, não há auto-correlação serial nos erros.

Fonte: Elaborada pelos autores. 
Inspecionando a Tabela 3, e considerando as especificações com controles, vemos que a predição fundamental sobre o sinal do coeficiente de interação entre BNDES/VTI e dep se verifica em todos os casos: o coeficiente é positivo para DFE (que captura dependência de finança externa), e negativo para K/VTI e IFE (que capturam independência). O padrão de sinais é mais perfeito no caso de K/VTI: além do sinal intuitivamente negativo do coeficiente de interação, temos que tanto o BNDES/VTI quanto o K/VTI têm, isoladamente, efeito positivo sobre a intensidade de P\&D.

Dentre os controles, vale destacar o impacto marginal positivo da abertura comercial e do investimento direto estrangeiro, com alta significância. Além deles, encontramos também, com menor significância, um impacto positivo do índice de Herfindahl-Hirschman, em conformidade com Aghion et al. (2005) e com teorias Schumpeterianas em geral, que postulam uma relação positiva entre poder de mercado e intensidade de P\&D a nível do setor da indústria.

Note ainda na Tabela 3 que, para todas as proxies de dep, o R-quadrado within aumenta quando acrescentamos os controles ao modelo de regressão. Em geral, o R-quadrado within também é maior que o between, o que, a nosso ver, favorece a interpretação de que um aumento do crédito do BNDES, nos setores com alta dependência de finança externa, favorece a atividade de P\&D.

Um outro aspecto a ser considerado, nas estimações do modelo em (7), é se não deveríamos incluir, do lado direito da equação, a variável dependente defasada. Do ponto de vista econômico, pensando numa persistência dos gastos em $P \& D$, isso não parece fazer sentido dada a baixa frequência dos dados (trienal). Do ponto de vista econométrico, tampouco parece se justificar a inclusão da variável dependente defasada: vemos pela Tabela 3 que os testes de Inoue-Solo não nos permitem rejeitar a hipótese nula de ausência de autocorrelação dos resíduos a níveis convencionais de significância $(1 \%$ ou $5 \%)$.

Finalmente, e ainda que o nosso foco de interesse seja o sinal do coeficiente do termo de interação, cumpre fazer um comentário sobre a interpretação das magnitudes dos coeficientes encontrados. Consideremos, no modelo em (7), o impacto marginal do crédito do BNDES sobre a intensidade em P\&D: 


$$
\frac{\partial(P \& D / V T I)}{\partial(B N D E S / V T I)}=\beta_{1}+\beta_{3} \cdot d e p
$$

Usando as estimativas obtidas na última coluna da Tabela 3, e igualando (9) a zero, obtemos o seguinte valor de limiar (threshold): IFE $=2,77$. De volta à Tabela 2 , constatamos que isso implica, para alguns setores $(2,11$, 16 e 19), um impacto negativo do crédito do BNDES sobre a intensidade de $P \& D$. Longe de constituir um puzzle, tal resultado indica apenas que esses setores deveriam receber menos recursos do BNDES, quando consideramos o P\&D como objetivo de política pública. ${ }^{18}$

\section{Robustez}

Como qualquer modelo de regressão, nossa Equação (7) poder estar sujeita a problemas de endogeneidade das variáveis explicativas, em particular do crédito do BNDES. Contudo, assim como Maskus et al. (2012) argumentam ser difícil imaginar fatores comuns determinando tanto a intensidade de $\mathrm{P} \& \mathrm{D}$ das indústrias quanto o grau de desenvolvimento financeiro de um país, também nós argumentamos que não há porque supor a intensidade de P\&D e o crédito do BNDES a nível setorial sendo determinados conjuntamente. ${ }^{19}$

O mesmo vale para uma possível "causalidade reversa", pela qual a intensidade de $P \& D$ determinaria o crédito do BNDES. Isso porque, em primeiro lugar, o P\&D representa uma fração pequena do investimento e do emprego total dos setores, não sendo de se esperar que constitua um objetivo principal do policy maker à testa do BNDES. ${ }^{20}$ Em segundo lugar, ainda

18 Tais valores de limiares, naturalmente, devem ser encarados com uma certa reserva. Usando o comando nlcom do programa Stata, encontramos um desvio-padrão alto (em torno de 0.5) para o threshold de 2,77 associado ao IFE.

19 Já não seria o caso numa análise ao nível das firmas. Pois, como sugerido por um parecerista anônimo, é razoável imaginar que empresas grandes são aquelas que ao mesmo tempo recebem mais crédito do BNDES e desenvolvem a atividade arriscada de P\&D. Ao nível dos setores CNAE, nós observamos pela Tabela 2 que a correlação média entre o índice de Herfindahl-Hirschman (que mede se um setor é mais concentrado que os outros) e a razão crédito do BNDES/VTI é razoavelmente pequena (14\%) - ou seja, o BNDES não parece conceder mais crédito para setores dominados por empresas grandes.

${ }^{20}$ Esse argumento não valeria caso nós usássemos, ao invés do crédito total do BNDES, o crédito earmarked para inovação. Quanto ao tamanho do gasto em P\&D como proporção do investimento em capital físico, sua média em nossa amostra (através de setores e de triênios) é $11 \%$. 
que as decisões de concessão de crédito do BNDES sigam critérios políticos afinados com rent-seeking (ver Lazzarini et al. 2015), não há porque imaginar que os setores com maior intensidade de P\&D sejam justamente aqueles com maior capacidade de fazer doações eleitorais e de assim contar com crédito do BNDES. ${ }^{21}$

Em todo caso, a fim de mitigar esse potencial problema de causalidade reversa, no apêndice $C$ nós reapresentamos os mesmos resultados da Tabela 3 acima, desta vez considerando em BNDES/VTI apenas o crédito que não é "earmarked" para inovação. Os resultados, em termos de sinais e magnitudes dos coeficientes, são muito parecidos com os da Tabela 3 porque a correlação entre as duas séries de BNDES/VTI (total e sem crédito para inovação) é da ordem de $97 \%$. Contudo, mesmo descartando a causalidade reversa direta da intensidade de P\&D para o crédito do BNDES, cumpre admitir a possibilidade de uma correlação positiva entre P\&D e investimento em capital físico, sendo que este último é o grande atractor de crédito do BNDES. ${ }^{22}$

Maskus et al. (2012) também discutem um problema de causalidade, ou melhor, de seleção, que poderia afetar a interpretação do sinal do coeficiente associado ao termo de interação. Adaptado para o nosso modelo em (7), o problema se coloca da seguinte maneira: e se crédito do BNDES alto "seleciona" alta dependência de finança externa, que por sua vez "seleciona" intensidade de P\&D alta? Contudo, inspecionando a coluna com controles referente a DFE na Tabela 3 acima, nota-se que o R-quadrado within é pelo menos tão grande quanto o R-quadrado between, o que não seria o caso se o coeficiente positivo associado ao termo de interação estivesse retratando majoritariamente o problema de seleção. Outra maneira de ver isso é analisando correlações quando o canal within está fechado, como na Tabela 2, seção 2, onde reportamos as médias (através dos triênios) das variáveis para cada setor: de fato, a correlação cross-sector entre DFE e intensidade em P\&D é positiva tal como em Maskus et al. (2012), mas pequena $(18,5 \%)$; a correlação entre DFE e BNDES/VTI também é positiva, mas pequena (17\%). Juntando as duas correlações positivas mas pequenas, o problema de seleção aventado por Maskus et al. (2012) não parece ser grave na nossa amostra. ${ }^{23}$

${ }^{21}$ Note que o argumento de economia política ou rent-seeking, tal como exposto por Lazzarini et al. (2015) perde força quando se utiliza dados a nível setorial, e não das firmas individuais.

22 Agradecemos a um parecerista anônimo por esta sugestão.

${ }^{23}$ Uma forte correlação negativa (DFE , BNDES/VTI) significaria que o BNDES concede crédito justamente àqueles setores com maior capacidade de repagar suas dívidas, contribuindo para uma credit 
Por todos esses motivos expostos acima, nós argumentamos aqui (tal como fazem Maskus et al. 2012) que não é necessário aplicar sobre a nossa especificação em (7) um tratamento por variáveis instrumentais.

Um problema que não pode ser desconsiderado é o da possível causalidade reversa do $P \& D$ para a dependência de finança externa ${ }^{24}$ ou, mais em geral, de não-exogeneidade dessa dependência - motivo pelo qual tanto Rajan e Zingales (1998) quanto Maskus et al. (2012) utilizam dados de dependência de setores dos EUA como proxies para a dependência dos setores correspondentes em outros países. Por este motivo, na Tabela 4 abaixo reestimamos nosso modelo de regressão básico (da Tabela 3) usando justamente as medidas de DFE de Rajan \& Zingales (disponíveis na última coluna da Tabela 2). ${ }^{25}$ A correlação com a DFE calculada para os setores da indústria brasileira é de 0.50 , o que torna a proxy razoável.

misallocation do tipo aventado por Lazzarini et al. (2015): restaria aos bancos e outras instituições privadas de crédito financiar setores (firmas) mais arriscados.

24 Afinal, uma parte (pequena, é verdade) da variável DFE é composta justamente pelo investimento em P\&D.

${ }^{25}$ Para isso, fizemos a concordância dos setores ISIC de Rajan e Zingales com os nossos setores CNAE. Infelizmente, não encontramos correspondência para o nosso setor 1 (indústria extrativa). 
Tabela 4 - Regressões com DFE de Rajan \& Zingales

\begin{tabular}{|c|c|c|}
\hline \multicolumn{3}{|c|}{ Dep = DFE Rajan \& Zingales } \\
\hline BNDES/VTI & $-1.2919^{* * *}$ & $-1.4096^{* *}$ \\
\hline & $(0.1004)$ & $(0.5397)$ \\
\hline \multirow[t]{2}{*}{ dep x BNDES/VTI } & $5.1807^{* * *}$ & $5.0604^{\star * *}$ \\
\hline & $(0.1702)$ & $(1.6169)$ \\
\hline \multirow[t]{2}{*}{ Abertura/VTI } & & $0.1968^{* * *}$ \\
\hline & & $(0.0336)$ \\
\hline \multirow[t]{2}{*}{ Invest.Direto Estrang./VTI } & & -0.2354 \\
\hline & & $(0.4849)$ \\
\hline \multirow[t]{2}{*}{ Capital Humano } & & -0.0381 \\
\hline & & $(0.0556)$ \\
\hline \multirow[t]{2}{*}{$\mathrm{IHH}$} & & $0.9977^{*}$ \\
\hline & & $(0.4828)$ \\
\hline \multirow[t]{2}{*}{ Constante } & $0.2953^{* * *}$ & -0.0335 \\
\hline & $(0.0307)$ & $(0.1831)$ \\
\hline No. Observações & 126 & 126 \\
\hline No. Setores & 21 & 21 \\
\hline Efeito Fixo Setor & Sim & Sim \\
\hline Efeito Fixo Ano & Sim & Sim \\
\hline Estimador Variância & Huber-White & Huber-White \\
\hline R-quadrado overall & 0,739 & 0,581 \\
\hline R-quadrado Between & 0,853 & 0,566 \\
\hline R-quadrado within & 0,627 & 0,701 \\
\hline Estat. F/Wald & 1772 & 4370 \\
\hline Prob & 0,0000 & 0,0000 \\
\hline teste LM de Inoue-Solo & 12,33 & 15,16 \\
\hline Prob(Inoue-Solo) & 0,195 & 0,087 \\
\hline
\end{tabular}

(1) Erro-padrão Robusto em parênteses.

(2) ${ }^{* * *} \mathrm{p}<0.01,{ }^{* *} \mathrm{p}<0.05,{ }^{*} \mathrm{p}<0.1$.

(3) Hipótese nula do teste de Inoue-Solo (2006) é de que, no painel, não há auto-correlação serial nos erros.

Fonte: Elaborada pelos autores. 
Cumpre notar que, como a variável de dependência de Rajan e Zingales (1998) não varia no tempo, na Tabela 4 estimamos o modelo sem o efeito isolado da variável de dependência (o $\beta_{2}$ da expressão 7), deixando isso ser capturado pelos efeitos fixos de setor, tal como em Maskus et al. (2012).

Inspecionando a Tabela 4, tanto na versão sem como na versão com controles, vemos que obtemos significância e o sinal positivo esperado para a interação entre o crédito do BNDES e a variável de dependência de finança externa. Relembrando que existe uma razoável correlação (50\%) entre a DFE dos setores brasileiros e a DFE de Rajan e Zingales, podemos concluir que nossos resultados não devem ser gravemente comprometidos por um problema de endogeneidade da variável de dependência.

\section{Conclusões}

Dentre os vários aspectos sob os quais o BNDES já foi avaliado, a atividade de $P \& D$ recebeu, de longe, menos atenção na literatura. Neste trabalho, procuramos analisar se o crédito do BNDES é mais positivamente correlacionado com a intensidade de $\mathrm{P} \& \mathrm{D}$ em setores da indústria ou períodos em que é maior a dependência de finança externa - afinal, por um lado, a atividade de $\mathrm{P} \& \mathrm{D}$ seria particularmente sujeita a imperfeições no mercado de crédito; e, por outro lado, uma das funções de um banco de desenvolvimento seria justamente compensar tais imperfeições.

A metodologia aqui empregada é uma adaptação da análise de regressão com interação de Rajan e Zingales (1998) e de Maskus et al. (2012). Essa metodologia nos parece particularmente adequada para analisar questões alocativas (no caso, do crédito do BNDES): não apenas se espera que o impacto do crédito seja em geral positivo, como se espera que ele seja mais forte onde há maior necessidade de crédito ou dependência de finança externa. A fim de captar esse efeito, neste trabalho se interagiu o crédito do BNDES (como proporção do valor da transformação industrial) com medidas de dependência de finança externa, ao nível do setor CNAE a 2 dígitos. O período analisado abrangeu os 6 triênios de dados disponibilizados pela PINTEC-IBGE. 
Utilizando as informações da PIA-IBGE e da PINTEC, construímos três proxies para dependência (ou independência) de finança externa: a famosa medida de Klapper et al. (2006), baseada na diferença entre o investimento e o fluxo de caixa livre das empresas; a relação entre o estoque de capital físico e o valor da transformação industrial (VTI), que se traduziria numa maior disponibilidade de colateral de crédito; e ainda uma medida de "liquidez" dada pela razão entre a receita líquida de vendas e o VTI.

Dentre essas proxies, todas apresentaram significância na análise de regressão com interação, sugerindo assim que o BNDES pode ter de fato desempenhado algum papel positivo ao compensar restrições de crédito, no que diz respeito a investimentos em P\&D. Em particular, vimos que nossos resultados são robustos quando utilizamos a medida de dependência de finança externa de Rajan e Zingales para os setores da indústria dos EUA, no lugar da medida análoga para os setores da indústria brasileira. Em geral, nossos resultados são robustos quando se controla para outras variáveis que se costuma considerar relevantes para a intensidade de P\&D: abertura comercial, investimento direto estrangeiro, capital humano e concentração (IHH) dos setores.

Cumpre ressaltar, contudo, uma limitação grave dos nossos resultados: eles são baseados em dados agregados ao nível dos setores CNAE, e não em microdados (ao nível das firmas). Não podemos, assim, fazer inferências causais a partir da correlação positiva entre crédito do BNDES e intensidade de $\mathrm{P} \& \mathrm{D}$, condicional à dependência de finança externa. Isso porque um efeito composição pode estar em ação: num mesmo setor, as firmas que mais receberam crédito do BNDES podem ser justamente aquelas que menos investiram em P\&D. ${ }^{26}$ Portanto, uma extensão natural deste artigo seria conduzir a mesma análise utilizando os microdados da PINTEC, da PIA e do BNDES.

${ }^{26}$ Agradecemos a um parecerista anônimo por ter apontado a possibilidade desse efeito composição. 


\section{Referências}

Aghion, Philippe; Nick Bloom ; Richard Blundell ; Rachel Griffith; Peter Howitt. "Competition and Innovation: an Inverted-U Relationship". The Quarterly Journal of Economics, Volume 120, Issue 2, 1 May 2005, Pages 701-728.

Alves, P. e Silva, A.M. 2008. "Estimativa do Estoque de Capital das Empresas Industriais Brasileiras". IPEA, TD No. 1325.

Ang., J.B., Jakob B. Madsen, Md. Rabiul Islam. "Catching up to the technology frontier: the dichotomy between innovation and imitation". The Canadian Journal of Economics / Revue canadienne d'Economique 43, no.4 (November / novembre 2010), pp. 1389-1411.

Armendáriz De Aghion, Beatriz. 1999. 'Development banking”. Journal of Development Economics 58: 83-100.

Bils, Mark; klenow, Peter J. 2000. "Does schooling cause growth?" American Economic Review 90, no. 5: 1160-1183.

Bond, Stephen; harhoff, Dietmar; Van Reenen, John. 2005. "Investment, R\&D and financial constraints in Britain and Germany". Annales d'Economie et de Statistique, n. 79/80: 433-460.

Bonomo, M.; Ricardo D. Brito e Bruno Martins. 2015. "The after crisis government-driven credit expansion in Brazil: A firm level analysis". Journal of International Money and Finance 55.

Brown, J.R., Fazzari, S.M., Petersen, B.C., 2009. 'Financing innovation and growth: cash flow, external equity, and the 1990s R\&D boom". The Journal of Finance 64: 151-185.

Carlin, W., Mayer, C., 2003. "Finance, investment, and growth". Journal of Financial Economics 69: 191-226.

Cavalcanti, Tiago \& Vaz, Paulo Henrique. 2017. "Access to long-term credit and productivity of small and medium firms: A causal evidence," Economics Letters, Elsevier, vol. 150(C), pages 21-25.

Correia de Souza, Eduardo; Rodrigo Menon Simões Moita. 2011. "Gasto em P\&D e poder de mercado: teoria e evidência para o Brasil”. Pesquisa e Planejamento Econômico, volume 41 | número 1 | abril 2011.

DeNegri, Joao Alberto, Alessandro Maffioli, Cesar M. Rodriguez, and Gonzalo Vázquez. 2011. "The Impact of Public Credit Programs on Brazilian Firms. IDB-WP-293 December 2011.

Ferreira, Pedro Cavalcanti; Galvao Jr., Antonio F.; Gomes, Fabio Augusto Reis; Pessoa, Samuel de Abreu. 2010. "The effects of external and internal shocks on total factor productivity". The Quarterly Review of Economics and Finance 50: 298-309.

Inklaar, Robert \& Koetter, Michael, 2008. "Financial dependence and industry growth in Europe: Better banks and higher productivity," GGDC Research Memorandum GD-100, Groningen Growth and Development Centre, University of Groningen.

Klapper, Leora; Laeven, Luc; Rajan, Raghuram. 2006. "Entry regulation as a barrier to entrepreneurship". Journal of Financial Economics 82: 591-629.

Lazzarini, Sergio G. \& Musacchio, Aldo \& Bandeira-de-Mello, Rodrigo \& Marcon, Rosilene, 2015. "What Do State-Owned Development Banks Do? Evidence from BNDES, 2002-09," World Development, Elsevier, vol. 66(C), pages 237-253.

Machado, Luciano; Parreiras, Maria Araújo; Peçanha, Vinícius Rodrigues. "Avaliação de impacto do uso do Cartão BNDES sobre o emprego nas empresas de menor porte". Biblioteca Digital do BNDES, 2011.

Machado, Luciano; Daniel da S. Grimaldi; Breno E. Albuquerque e Leonardo de O. Santos. "Additionality of Countercyclical Credit: Evaluating the Impact of BNDES' PSI on the Investment of Industrial Firms". Working Paper BNDES 2014.

Machado, Luciano; Ricardo A. Martini. "BNDES Effects on Firms' Innovation: Evidence from Brazilian Panel Data”. Working Paper BNDES 2019.

Maskus, Keith E.; Neumann, Rebecca; Seidel, Tobias. 2012. "How national and international financial development affect industrial R\&D”. European Economic Review 56, no. 1: 72-83. 
Rajan, Raghuram G.; Zingales, Luigi. 1998. "Financial dependence and growth". American Economic Review 88, no.3: 559-586.

Ribeiro, Eduardo P.; DeNegri, João A. 2009. "Public credit use and manufacturing productivity in Brazil". ResearchGate.

Sousa, Filipe Lage de; Ottaviano, Gianmarco I. P. 2018. "Relaxing credit constraints in emerging economies: the impact of public loans on the productivity of Brazilian manufacturers". Rio de Janeiro: Banco Nacional de Desenvolvimento Econômico e Social, 58 p. (Discussion papers; 124)

Stiglitz, Joseph E. 1994. The role of the state in financial markets (English). Washington, D.C.: The World Bank.

\section{APÊNDICE A - correspondência entre classificações de setores industriais}

\begin{tabular}{|c|c|c|}
\hline Código e Classificação do trabalho & Código e Determinação CNAE 2.0 & $\begin{array}{l}\text { Código e Determinação } \\
\text { CNAE } 1.0\end{array}$ \\
\hline 1 - Indústrias Extrativas & $\begin{array}{l}05 \text { - Extração de Carvão Mineral } \\
06 \text { - Extração de Petróleo E Gás } \\
\text { Natural } \\
07 \text { - Extração de Minerais Metálicos } \\
08 \text { - Extração de Minerais Não-Me- } \\
\text { tálicos } \\
09 \text { - Atividades de Apoio à Extração } \\
\text { de Minerais }\end{array}$ & $\begin{array}{l}10 \text { - Extração de Carvão } \\
\text { Mineral } \\
11 \text { - Extração de Petróleo e } \\
\text { Serviços Correlatos } \\
13 \text { - Extração de Minerais } \\
\text { Metálicos } \\
14 \text { - Extração de Minerais } \\
\text { Não-Metálicos }\end{array}$ \\
\hline $\begin{array}{l}2 \text { - Fabricação de Bebidas e Pro- } \\
\text { dutos Alimentícios }\end{array}$ & $\begin{array}{l}10 \text { - Fabricação de Produtos Ali- } \\
\text { mentícios } \\
11 \text { - Fabricação de Bebidas }\end{array}$ & $\begin{array}{l}15 \text { - Fabricação de Produtos } \\
\text { Alimentícios e Bebidas }\end{array}$ \\
\hline $\begin{array}{l}3 \text { - Fabricação de Produtos do } \\
\text { Fumo }\end{array}$ & $\begin{array}{l}12 \text { - Fabricação de Produtos do } \\
\text { Fumo }\end{array}$ & $\begin{array}{l}16 \text { - Fabricação de Produtos } \\
\text { do Fumo }\end{array}$ \\
\hline 4 - Fabricação de Produtos Têxteis & 13 - Fabricação de Produtos Têxteis & $\begin{array}{l}17 \text { - Fabricação de Produtos } \\
\text { Têxteis }\end{array}$ \\
\hline $\begin{array}{l}5 \text { - Confecção de Artigos do Ves- } \\
\text { tuário e Acessórios }\end{array}$ & $\begin{array}{l}14 \text { - Confecção de Artigos do Ves- } \\
\text { tuário e Acessórios }\end{array}$ & $\begin{array}{l}18 \text { - Confecção de Artigos do } \\
\text { Vestuário e Acessórios }\end{array}$ \\
\hline $\begin{array}{l}6 \text { - Preparação de Couros e Fa- } \\
\text { bricação de Artefatos de Couro, } \\
\text { Artigos para Viagem e Calçados }\end{array}$ & $\begin{array}{l}15 \text { - Preparação de Couros e Fabri- } \\
\text { cação de Artefatos de Couro, Artigos } \\
\text { para Viagem e Calçados }\end{array}$ & $\begin{array}{l}19 \text { - Preparação de Couros } \\
\text { e Fabricação de Artefatos de } \\
\text { Couro, Artigos de Viagem e } \\
\text { Calçados }\end{array}$ \\
\hline $\begin{array}{l}7 \text { - Fabricação de Produtos de } \\
\text { Madeira }\end{array}$ & $\begin{array}{l}16 \text { - Fabricação de Produtos de } \\
\text { Madeira }\end{array}$ & $\begin{array}{l}20 \text { - Fabricação de Produtos } \\
\text { de Madeira }\end{array}$ \\
\hline $\begin{array}{l}8 \text { - Fabricação de Celulose, Papel } \\
\text { e Produtos de Papel }\end{array}$ & $\begin{array}{l}17 \text { - Fabricação de Celulose, Papel } \\
\text { e Produtos de Papel }\end{array}$ & $\begin{array}{l}21 \text { - Fabricação de Celulose, } \\
\text { Papel e Produtos de Papel }\end{array}$ \\
\hline $\begin{array}{l}9 \text { - Impressão e Reprodução de } \\
\text { Gravações }\end{array}$ & $\begin{array}{l}18 \text { - Impressão e Reprodução de } \\
\text { Gravações }\end{array}$ & $\begin{array}{l}22 \text { - Edição, Impressão e } \\
\text { Reprodução de Gravações }\end{array}$ \\
\hline $\begin{array}{l}10 \text { - Fabricação de Coque, de } \\
\text { Produtos Derivados do Petróleo e } \\
\text { de Biocombustíveis }\end{array}$ & $\begin{array}{l}19 \text { - Fabricação de Coque, de Pro- } \\
\text { dutos Derivados do Petróleo e de } \\
\text { Biocombustíveis }\end{array}$ & $\begin{array}{l}23 \text { - Fabricação de Coque, } \\
\text { Refino de Petróleo, Elabora- } \\
\text { ção de Combustíveis Nuclea- } \\
\text { res e Produção de Álcool }\end{array}$ \\
\hline $\begin{array}{l}11 \text { - Fabricação de Produtos Quí- } \\
\text { micos, Farmoquímicos e Farma- } \\
\text { cêuticos }\end{array}$ & $\begin{array}{l}20 \text { - Fabricação de Produtos Quí- } \\
\text { micos } \\
21 \text { - Fabricação de Produtos Farmo- } \\
\text { químicos e Farmacêuticos }\end{array}$ & $\begin{array}{l}24 \text { - Fabricação de Produtos } \\
\text { Químicos }\end{array}$ \\
\hline $\begin{array}{l}12 \text { - Fabricação de Produtos de } \\
\text { Borracha e de Material Plástico }\end{array}$ & \begin{tabular}{|l|}
22 - Fabricação de Produtos de \\
Borracha e de Material Plástico
\end{tabular} & $\begin{array}{l}25 \text { - Fabricação de Artigos de } \\
\text { Borracha e Plástico }\end{array}$ \\
\hline
\end{tabular}




\begin{tabular}{|c|c|c|}
\hline $\begin{array}{l}13 \text { - Fabricação de Produtos de } \\
\text { Minerais Não-Metálicos }\end{array}$ & $\begin{array}{l}23 \text { - Fabricação de Produtos de } \\
\text { Minerais Não-Metálicos }\end{array}$ & $\begin{array}{l}26 \text { - Fabricação de Produtos } \\
\text { de Minerais Não-Metálicos }\end{array}$ \\
\hline 14 - Metalurgia & 24 - Metalurgia & 27 - Metalurgia Básica \\
\hline $\begin{array}{l}15 \text { - Fabricação de Produtos de } \\
\text { Metal, Exceto Máquinas e Equi- } \\
\text { pamentos }\end{array}$ & $\begin{array}{l}25 \text { - Fabricação de Produtos de } \\
\text { Metal, Exceto Máquinas e Equipa- } \\
\text { mentos }\end{array}$ & $\begin{array}{l}28 \text { - Fabricação de Produtos } \\
\text { de Metal-Exclusive Máquinas } \\
\text { e Equipamentos }\end{array}$ \\
\hline $\begin{array}{l}16 \text { - Fabricação de Equipamentos } \\
\text { de Informática, Produtos Eletrôni- } \\
\text { cos e Ópticos }\end{array}$ & $\begin{array}{l}26 \text { - Fabricação de Equipamentos } \\
\text { de Informática, Produtos Eletrônicos } \\
\text { e Ópticos }\end{array}$ & $\begin{array}{l}30 \text { - Fabricação de Maquinas } \\
\text { para Escritório e Equipamen- } \\
\text { tos de Informática } \\
33 \text { - Fabricação de Equipa- } \\
\text { mentos de Instrumentação } \\
\text { Médico-Hospitalares, Ins- } \\
\text { trumentos de Precisão e } \\
\text { Ópticos, Equipamentos para } \\
\text { Automação Industrial, Cronô- } \\
\text { metros e Relógios }\end{array}$ \\
\hline $\begin{array}{l}17 \text { - Fabricação de Máquinas, } \\
\text { Aparelhos e Materiais Elétricos }\end{array}$ & $\begin{array}{l}27 \text { - Fabricação de Máquinas, Apa- } \\
\text { relhos e Materiais Elétricos }\end{array}$ & $\begin{array}{l}31 \text { - Fabricação de Maqui- } \\
\text { nas, Aparelhos e Materiais } \\
\text { Elétricos }\end{array}$ \\
\hline $\begin{array}{l}18 \text { - Fabricação de Máquinas e } \\
\text { Equipamentos }\end{array}$ & $\begin{array}{l}28 \text { - Fabricação de Máquinas e } \\
\text { Equipamentos }\end{array}$ & $\begin{array}{l}29 \text { - Fabricação de Maquinas } \\
\text { e Equipamentos }\end{array}$ \\
\hline $\begin{array}{l}19 \text { - Fabricação de Veículos Auto- } \\
\text { motores, Reboques e Carrocerias }\end{array}$ & $\begin{array}{l}29 \text { - Fabricação de Veículos Auto- } \\
\text { motores, Reboques e Carrocerias }\end{array}$ & $\begin{array}{l}34 \text { - Fabricação e Montagem } \\
\text { de Veículos Automotores, } \\
\text { Reboques e Carrocerias } \\
\end{array}$ \\
\hline Código e Classificação do trabalho & Código e Determinação CNAE 2.0 & $\begin{array}{l}\text { Código e Determinação } \\
\text { CNAE 1.0 }\end{array}$ \\
\hline $\begin{array}{l}20 \text { - Fabricação de Outros Equi- } \\
\text { pamentos de Transporte, Exceto } \\
\text { Veículos Automotores }\end{array}$ & $\begin{array}{l}30 \text { - Fabricação de Outros Equipa- } \\
\text { mentos de Transporte, Exceto Veí- } \\
\text { culos Automotores }\end{array}$ & $\begin{array}{l}35 \text { - Fabricação de Outros } \\
\text { Equipamentos de Transporte }\end{array}$ \\
\hline 21 - Fabricação de Móveis & 31 - Fabricação de Móveis & $\begin{array}{l}36 \text { - Fabricação de Moveis e } \\
\text { Industrias Diversas }\end{array}$ \\
\hline $\begin{array}{l}22 \text { - Fabricação de Produtos Di- } \\
\text { versos }\end{array}$ & $\begin{array}{l}32 \text { - Fabricação de Produtos Di- } \\
\text { versos } \\
33 \text { - Manutenção, Reparação e } \\
\text { Instalação de Máquinas e Equipa- } \\
\text { mentos }\end{array}$ & $\begin{array}{l}32 \text { - Fabricação de Material } \\
\text { Eletrônico e de Aparelhos e } \\
\text { Equipamentos de Comuni- } \\
\text { cações } \\
37 \text { - Reciclagem }\end{array}$ \\
\hline
\end{tabular}

Fonte: Elaborado pelos autores. 
APÊNDICE B - Demais gráficos (da seção 2)

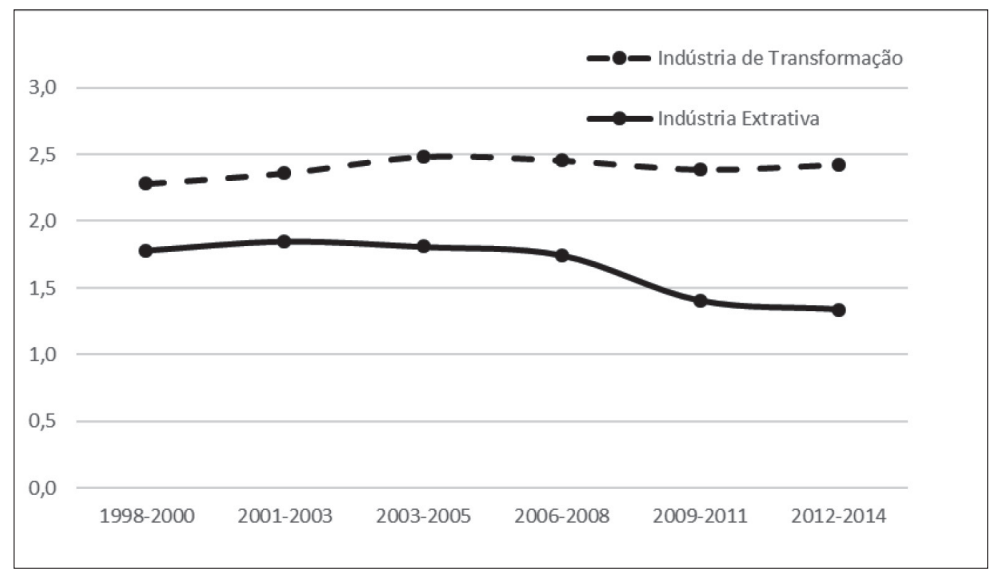

\section{Gráfico B1 - IFE}

Fonte: Elaborado pelos autores, a partir da PIA-IBGE.

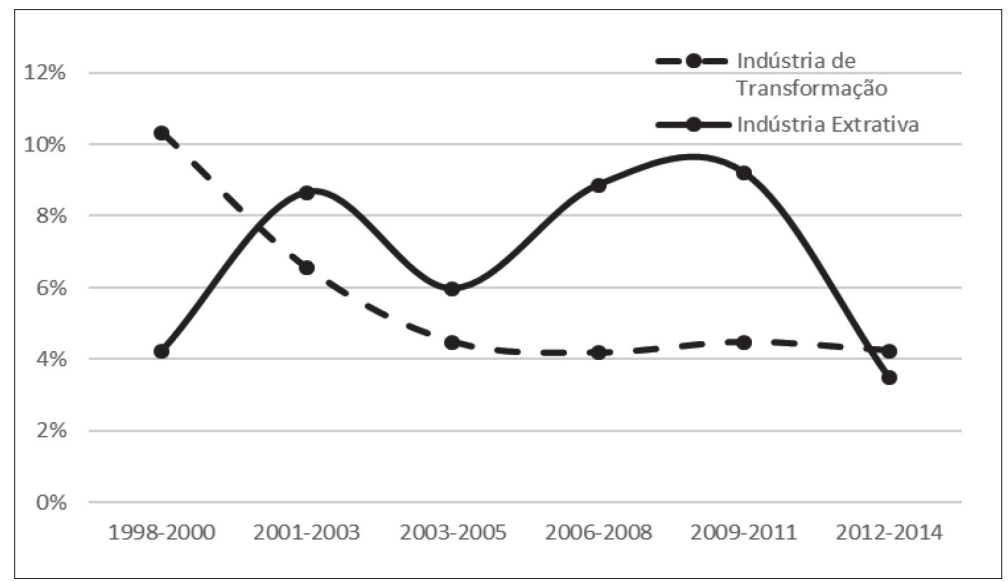

\section{Gráfico B2 - IDE}

Fonte: elaborado pelos autores, a partir de dados do Banco Central do Brasil. 


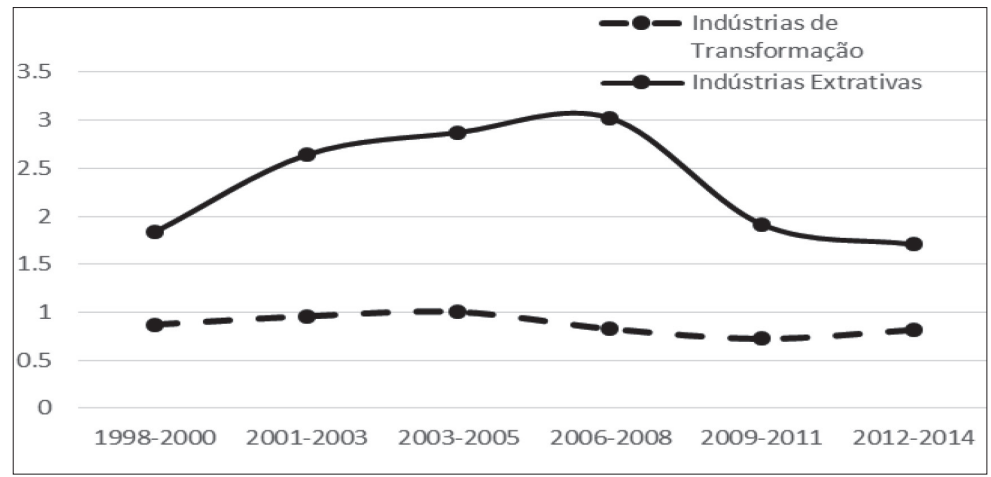

Gráfico B3 - Exportação + Importação por VTI

Fonte: Elaborado pelos autores, a partir de dados da Funcex.

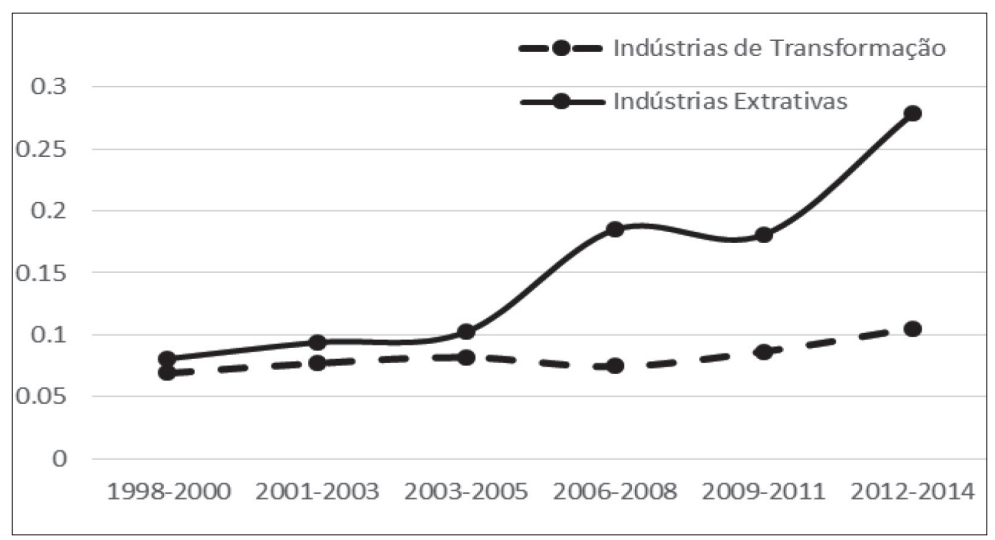

Gráfico B4 - Proporção dos trabalhadores com nível superior

Fonte: Elaborado pelos autores, a partir de dados da RAIS. 


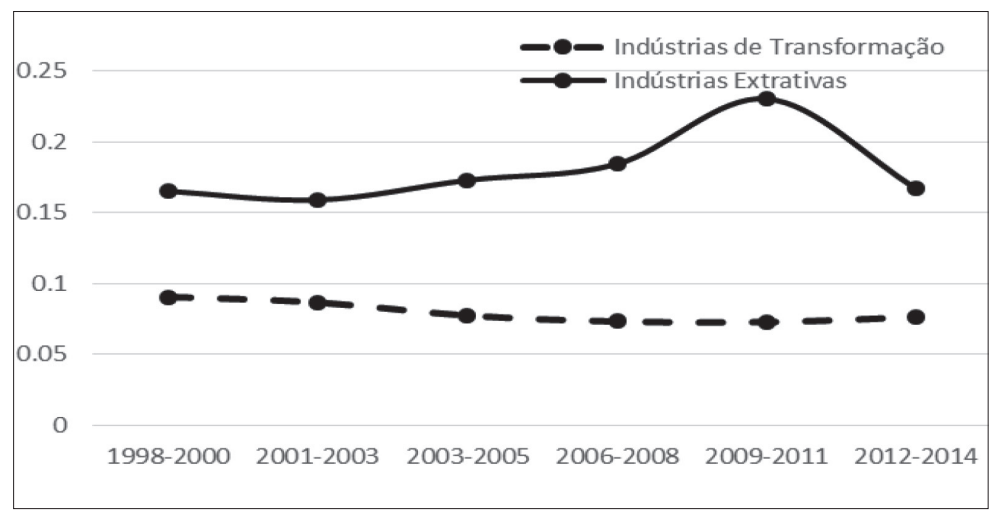

Gráfico B5 - HHI

Fonte: Elaborado pelos autores, a partir de tabulação na SAR-IBGE. 
APÊNDICE C - uma versão da tabela 3 utilizando apenas os créditos do BNDES não earmarked para inovação

\begin{tabular}{|c|c|c|c|c|c|c|}
\hline \multirow{2}{*}{ BNDES/VTI } & \multicolumn{2}{|c|}{ dep $=$ DFE } & \multicolumn{2}{|c|}{$\operatorname{dep}=\mathrm{K} / \mathrm{VTI}$} & \multicolumn{2}{|c|}{ dep $=$ IFE } \\
\hline & 1,2945 & $0,8903^{* *}$ & $0,3894^{* * *}$ & $0,3780^{* * *}$ & $2,4257^{* *}$ & $2,0115^{* \star *}$ \\
\hline & $(0,8118)$ & $(0,3855)$ & $(0,0350)$ & $(0,0620)$ & $(0,8757)$ & $(0,2981)$ \\
\hline \multirow{2}{*}{ dep } & $-0,0193$ & $-0,0190$ & $0,0333^{* * *}$ & $0,0437^{* * *}$ & $-0,1443$ & $-0,0658$ \\
\hline & $(0,0187)$ & $(0,0136)$ & $(0,0021)$ & $(0,0093)$ & $(0,3028)$ & $(0,1430)$ \\
\hline \multirow{2}{*}{ dep x BNDES/VTI } & 0,7199 & $0,6434^{\star *}$ & $-0,0217^{* * *}$ & $-0,0246$ & $-0,7810^{* * *}$ & $-0,6956^{\star \star *}$ \\
\hline & $(0,4933)$ & $(0,2707)$ & $(0,0040)$ & $(0,0305)$ & $(0,2611)$ & $(0,1308)$ \\
\hline \multirow{2}{*}{ Abertura/VTI } & & $0,2685^{\star \star *}$ & & $-0,1444^{*}$ & & $0,2555^{\star * *}$ \\
\hline & & $(0,0776)$ & & $(0,0826)$ & & $(0,0809)$ \\
\hline \multirow{2}{*}{ Invest, Direto Estrang,/VTI } & & $0,5074^{\star *}$ & & $-0,3657$ & & $0,6064^{* * *}$ \\
\hline & & $(0,1911)$ & & $(0,6191)$ & & $(0,1644)$ \\
\hline \multirow{2}{*}{ Capital Humano } & & $-0,0737$ & & 0,0294 & & $-0,0287$ \\
\hline & & $(0,0590)$ & & $(0,0368)$ & & $(0,0591)$ \\
\hline \multirow[t]{2}{*}{$\mathrm{HHI}$} & & $0,8532^{*}$ & & 0,4063 & & $-0,0049$ \\
\hline & & $(0,4116)$ & & $(0,3201)$ & & $(0,7766)$ \\
\hline \multirow{2}{*}{ Constante } & $0,3025^{\star * *}$ & $-0,2512$ & $0,1362^{* * *}$ & $0,2790^{\star *}$ & 0,6602 & 0,1284 \\
\hline & $(0,0533)$ & $(0,2192)$ & $(0,0182)$ & $(0,1271)$ & $(0,6924)$ & $(0,3889)$ \\
\hline No, Observações & 132 & 132 & 132 & 132 & 132 & 132 \\
\hline No, Setores & 22 & 22 & 22 & 22 & 22 & 22 \\
\hline Efeito Fixo Setor & Sim & Sim & Sim & Sim & Sim & Sim \\
\hline Efeito Fixo Ano & Sim & Sim & Sim & Sim & Sim & Sim \\
\hline Estimador Variância & Huber-White & Huber-White & Huber-White & Huber-White & Huber-White & Huber-White \\
\hline R-quadrado overall & 0,420 & 0,481 & 0,735 & 0,506 & 0,118 & 0,557 \\
\hline R-quadrado between & 0,468 & 0,445 & 0,706 & 0,299 & 0,0183 & 0,573 \\
\hline R-quadrado within & 0,383 & 0,632 & 0,773 & 0,798 & 0,307 & 0,567 \\
\hline Estat, $\mathrm{F}$ & 8,524 & 153,2 & 8244 & 43504 & 4,571 & 559,6 \\
\hline Prob (F) & 0,0000 & 0,0000 & 0,0000 & 0,0000 & 0,0024 & 0,0000 \\
\hline teste LM de Inoue-Solo & 6,90 & 12,93 & 16,07 & 15,86 & 9,35 & 9,31 \\
\hline Prob(Inoue-Solo) & 0,648 & 0,166 & 0,066 & 0,070 & 0,406 & 0,409 \\
\hline
\end{tabular}

(1) Erro-padrão Robusto em parênteses.

(2) ${ }^{* * *} \mathrm{p}<0.01,{ }^{* *} \mathrm{p}<0.05,{ }^{*} \mathrm{p}<0.1$.

(3) Hipótese nula do teste de Inoue-Solo (2006) é de que, no painel, não há auto-correlação serial nos erros. 